\title{
LA SOCIEDAD CUBANAA FINALES DE LOS 70: PRODUCCIÓN ARTÍSTICA E IDEOLOGÍA REVOLUCIONARIA EN FRESA Y CHOCOLATE (1993)
}

Ana María DRAGHIA

Universidad de Alicante

\section{RESUMEN}

Fresa y chocolate (1993) presenta la realidad socio-política de Cuba en los años 70. A través de la película pretendemos recoger aquellas muestras de represión cultural, religiosa, política e incluso sexual. La simbología del largometraje apoya las diferentes formas de búsqueda de la libertad que los protagonistas de la película buscan para escapar de la opresión, pero también sirven para construir la sociedad del momento. Así, analizaremos diferentes secuencias y símbolos del film para intentar reconstruir el contexto político y artístico de la época.

Palabras clave: Revolución, Cuba, Fresa y chocolate, censura.

\section{ABSTRACT}

Fresa y chocolate presents the social and political reality of Cuba in the 70s. Throughout the film, we aim to identify those clues of cultural, religious, politic and even sexual repression. The symbology of the film sustains the different forms of seeking the freedom that the protagonists of the movie pursue in order to escape from the oppression, but it also helps to build the society of that moment. Thus, we analyze different sequences and symbols of the film to try to rebuild the political and artistic context of the time.

Keywords: Revolution, Cuba, Strawberry and Chocolate, censorship.

\section{INTRODUCCIÓN}

A finales de la década de los setenta, cuando la represión cultural comenzó a menguar, fue difícil desvincular la producción artística de la ideología revolucionaria que Fidel Castro manifestó en «Palabras a los intelectuales». Sin embargo, los escritores y los artistas no fueron 
los únicos atenazados por la coyuntura de las preguntas que se derivaron de este discurso. La discusión principal circundaba el hecho de si debía haber una absoluta libertad en cuanto al contenido de la expresión artística y si la Revolución estaría regida por la censura. Las consecuencias de la política que se implantaría son imprescindibles para comprender el contexto socio-político de la película de Tomás Gutiérrez Alea y Juan Carlos Tabío: Fresa y chocolate (1993), basada en el relato de Senel Paz El lobo, el bosque y el hombre nuevo.

La trama del largometraje sigue una narración lineal que rescata la búsqueda de la libertad intelectual, sentimental y artística, al tiempo que las palabras de José Martí cubren los muros de un periodo social y cultural empañado por la urgencia de saber hasta cuándo se prolongaría la reclusión de los cubanos en su propio país. Aislados en "La Guarida" -espacio ficticio que se crea dentro de la película-, los protagonistas intentarán dar respuesta a las cuestiones religiosas, políticas y literarias que se desprenden de su realidad. Tras unas paredes empapeladas con imágenes de vírgenes, santos y fotografías de Lezama Lima - Charles Dickens, a ratos pasan por alto que las calles están cubiertas de los panfletos revolucionarios de Fidel Castro en contra de la dictadura de Fulgencio Batista. Así las cosas, a través de esta coproducción de Cuba-México-España queremos dar cuenta de la producción artística y literaria que se fragua en una Habana escindida entre comunistas y revolucionarios marxistas con el fin de comprender mejor la sociedad del momento y las cuestiones culturales en que se ve envuelta.

\section{RELACIONES ENTRE CINE Y LITERATURA}

La mayor parte de las películas o cortos tienen como precedente un material literario, ya sea teatro o novela, que con el paso de los años ha cobrado mayor interés para los productores, pero también para los espectadores.

Cualquier relato, para ser narrado en forma de film, ha debido estructurarse siguiendo el patrón de la novela decimonónica, solo esporádica y tardíamente (fue) sustituido por otros patrones más recientes (nouveau roman francés, técnica del monólogo interior, etc.). Ahora bien, con ser ello cierto solo concierne a la estructura dramática del relato y al desmenuzamiento de los hechos mediante la planificación y el montaje; pero la materia esencial sobre la que operan aquella estructura y aquel desmenuzamiento es desde luego distinta en la novela y en el film: el material de una novela son las palabras, el material de una películas son las imágenes (1985: 49-50).

Esta última idea, que de manera tan acertada recoge Pere Gimferrer, es el eje sobre el que deben circundar las cuestiones que recojamos a lo largo de nuestro análisis. No debemos obviar en ningún momento las diferencias existentes entre un tipo de arte y otro, aunque tampoco debemos desmerecer la relación inherente que se manifiesta entre ambos. Entre las diferencias a las que hemos de referirnos, dejando a un lado la más evidente de ellas -el soporte-, se encuentra el lenguaje narrativo empleado en el cine, que es mucho menos complejo que el que podemos diferenciar en cualquier novela con cierto nivel literario. Evidentemente, no se pueden sustraer aquellos elementos que pertenecen propiamente a la palabra y llevarlos al lenguaje fílmico, y esto supone que el problema de la adaptación se acreciente: «Una adaptación genuina debe consistir en que, por los medios que le son 
propios - la imagen- el cine llegue a producir en el espectador un efecto análogo al que mediante el material verbal -la palabra- produce la novela en el lector» (1985: 61). Esto es, precisamente, lo que se consigue con la adaptación del cuento de Senel Paz.

\section{SENEL PAZ: EL LOBO, EL BOSQUE Y EL HOMBRE NUEVO}

Senel Paz (Las Villas, 1950) es un escritor y guionista cubano que nació en el seno de una familia pobre, pero su vida dio un giro rotundo cuando, tras triunfar la Revolución cubana, su madre consiguió un trabajo mejor que les hizo emerger de la paupérrima situación en la que se hallaban. En 1973, y después de mucho esfuerzo, se licenció en periodismo por la Universidad de La Habana. Dio sus primeros pasos en el mundo laboral gracias al periódico Adelante, la UNEAC o el Departamento de Divulgación del Ministerio de Cultura cubana, aunque su obra literaria ha estado siempre asociada a su faceta como guionista y escritor teatral. Así pues, es probable que el relato que nos ocupa esté plagado de técnicas cinematográficas debido a estas últimas características.

El lobo, el bosque y el hombre nuevo es el cuento que sirvió como base para la creación del guion cinematográfico de Fresa y chocolate. Como dato anecdótico cabe decir que este relato fue el texto más fotocopiado de la historia de Cuba, y acabó por ser editado en una veintena de países, traducido a once idiomas y adaptado a diecinueve versiones teatrales diferentes. Esto supuso un antes y un después en la carrera de Senel Paz, abriéndole nuevas puertas y, además, sirviéndole para dar voz a toda una generación de cubanos. Pero ¿qué encierra su cuento para que supusiera esta revolución a la que nos referimos?

El relato narra la historia de una amistad peculiar entre dos jóvenes cubanos a finales de la década de los setenta (1979). Este se divide en tres partes, marcadas por la estructura clásica: introducción, desarrollo y desenlace. El texto, plagado de recursos cinematográficos, como flashbacks, primeros planos y planos generales, emplea el lenguaje para crear una historia circular, en la que la narración comienza y concluye de la misma manera. Por tanto, distinguimos una primera parte, que tiene lugar en un momento presente; una segunda parte, que constituye una vuelta al pasado para narrar la historia, que surge mediante un recuerdo del protagonista, y una tercera y última parte en la que la voz narrativa regresa al presente.

Por otro lado, en cuanto a la estructura interna, debemos referirnos primeramente al argumento de la historia. David, un joven perteneciente a una familia humilde, gracias a su colaboración en la Juventud Revolucionaria, logra una beca de estudios en la Universidad de La Habana, en concreto en ciencias políticas. Aferrado a las ideas del comunismo, que nunca llega a despreciar, conoce a Diego, un joven profesor de arte perteneciente a la antigua clase burguesa. Diego, marginado por David por su ideología política y por su orientación sexual, a medida que la acción avanza, consigue abrir la mente a David, dejando cabida a otros modos de pensar, pero también de sentir. No hay en la película, sin embargo, acciones de relevancia extraordinaria. La trama sigue una línea continua en la que son los personajes quienes experimentan un cambio, en concreto David. Ese cambio viene dado no tanto por unos hechos concretos como por un pensamiento diferente, el de Diego. El tema, pues, podemos decir que es la búsqueda de la libertad, tanto intelectual como sentimental y artística. Observamos, en definitiva, que el hilo argumental y temático de la película es fiel al que presenta el cuento. Pero, hemos de discernir también las diferencias y similitudes que existe entre la versión literaria y la fílmica. Evidentemente, al ser el propio Senel Paz el que 
ha llevado a término la reescritura del cuento, las variaciones deberían ser mínimas, pero apreciaremos que no ocurre exactamente así.

La desvinculación de David del Gobierno está fuertemente marcada por la concepción que tiene del arte. Tanto él, como quien para él es su maestro, Lezama Lima, insistían en que el arte como tal no debe tener función política. Lezama pensaba que la poesía tenía su propia realidad y que solo obedecía a sus propias leyes internas. Sin embargo, dentro de la sociedad cubana de finales de la década de los setenta, cuando la represión cultural comienza a menguar, fue muy difícil desvincular la producción artística de la ideología revolucionaria que Fidel Castro proclamó en «Palabras a los intelectuales». Se han recogido centenares de noticias que reescriben las consecuencias de la política que se implantó, y que es imprescindible para el entendimiento del contexto socio-político del cuento, y, por supuesto, de la película.

La censura, pues, formaba parte indivisible de la realidad socio-cultural que estaba viviendo Cuba en aquellos años. De este modo, esta política restrictiva acabó por llevar, en la primera mitad de los setenta, la literatura cubana desde el punto más álgido hasta el más bajo de su historia literaria. Senel Paz, mediante su escrito, pretende poner de manifiesto las cuestiones tratadas hasta el momento, y para ello, mediante la alusión constante a escritores, músicos y artistas, expone sin tapujos la realidad de unos años imborrables de la historia de Cuba.

\section{LA SIMBOLOGÍA DE LA CUESTIÓN POLÍTICO-SOCIAL DE CUBA EN FRESA $Y$ CHOCOLATE}

En primer lugar, no podemos hablar de la película sin referirnos al papel desempeñado por los directores. Tomás Gutiérrez Alea (La Habana, 1928-1996), apodado Titón, fue uno de los más importantes cineastas cubanos, que dirigió y escribió más de una veintena de cortos, largometrajes y documentales a lo largo de su carrera. Su trabajo más representativo tuvo lugar, precisamente, en la década que va de los años sesenta a los setenta; un periodo este que acabó por conocerse como Nuevo Cine Latinoamericano -o también Cine Nuevo o Cine Imperfecto-. Su interés principal se centró en los problemas surgidos del neocolonialismo, pero no menos importante fue la identidad cultural, que sigue en la estela de la otredad. Los directores de esta nueva línea creativa, como ocurría en teatro, pretendían involucrar al espectador en la realidad de los problemas que transmitían a través de sus films, y Gutiérrez Alea no fue una excepción a esta regla. Entre sus trabajos más importantes destacan Muerte de un burócrata (1966) -con alusiones a Luis Buñuel o Buster Keaton entre otros-; Memorias del subdesarrollo (1968), Fresa y chocolate (1993) y Guantanamera (1995), las dos últimas coproducidas con nuestro segundo director: Juan Carlos Tabío (1943, La Habana).

Con respecto a Fresa y chocolate, nominada al Oscar en 1994 a la mejor película de habla no inglesa, ha sido considerada como una de las producciones cinematográficas más polémicas de la década de los noventa, pero esto no supuso un impedimento para obtener el Premio Teddy en el Festival de Berlín de 1994; el Goya a la mejor película hispanoamericana; cuatro Premios ACE y seis premios en el Festival de Gramado, entre muchísimos otros. Tan aclamada fue, y a la vez, como anunciábamos, tan polémica que hoy en día sigue representando un punto de referencia para la defensa de los derechos humanos, como se recoge en el periódico $A B C$ de Toledo: 
El fenómeno de la persecución por razones de sexo o ideas políticas es una tragedia que aún afecta a muchos países y culturas. Por este motivo CiBRA, al celebrar los veinte años del estreno de Fresa y chocolate, se suma a la lucha por desterrar toda forma de discriminación del mundo. El festival del Cine y la Palabra rinde tributo a la película valiente que desde la pantalla lanzó un grito por la libertad y los derechos humanos (M.V., ABC: 11 de noviembre del 2013).

Las diferentes secuencias muestran esta persecución de la libertad a través de la realidad social de Cuba desde el mismo comienzo de la película. Así, en la secuencia cinco vemos que Diego se acerca a David, quien está comiendo un helado de fresa, símbolo, junto al chocolate, que marcará la dualidad de la película entre la tradición y el cambio. Afirma: «Es lo único bueno que hacen en este país», por lo que, desde el primer momento, se abre la polémica de la situación socio-cultural cubana. Llama la atención esta escena no solo por la intervención que este personaje hace, sino también por el ejemplar de Conversación en la catedral de Mario Vargas Llosa. David no le quita ojo al ejemplar, y al igual que ocurre en el cuento, aunque omitiendo la última parte, Diego le pregunta: «¿Te interesa Vargas Llosa?». En el cuento la pregunta se cierra con un interesante detalle que nos hace percibir ya los bandos a los que pertenece cada personaje: « $i T e$ interesa Vargas Llosa, amigo compañero militante de la Juventud?» (Paz, 2006: 13). Diego le invita a su casa para mostrarle más libros, David se niega y hace pasar de un bolsillo a otro de su camisa su carné de militante, una manera clara de marcar las distancias entre ambos. Diego, entre divertido e irónico, da cuenta de la censura del país y de la autocensura que el propio David, como representante de todo un colectivo, manifiesta diciendo: «Solo puedes leer los libros de la Juventud». Aquí es precisamente donde se presenta la verdadera crudeza de la censura intelectual.

En esta secuencia, asimismo, sale a la luz la faceta de actor de David, que representó el papel de Torvaldo de Casa de muñecas, de Henrik Ibsen. En el cuento, se produce un flashback en el que David cuenta con detalle cómo fue esta experiencia para él, y hace una cruda reflexión que, lejos de ser baladí, apoya la sentencia anterior de Diego. Dice sobre la obra de lbsen que «estaba libre de ponzoñas ideológicas y figuraba en el programa de estudios revisado por el Ministerio» (Paz, 2006: 14). Diego aprovecha este momento para revelar que posee unas supuestas fotos que le sacó en la representación de la obra. Con ello consigue convencerle para que acuda a su casa. Sin duda es el punto de la inflexión en las ideologías de ambos.

A lo largo de la película, la simbología es variada, no solo a través de la selección literaria que se hace, sino también por medio de la imaginería religiosa o algo tan sencillo como la fresa y el chocolate ya mencionada o el té y el café. De hecho, Diego llega a afirmar: "La bebida de la gente civilizada es el té, pero nosotros no. Nosotros preferimos el café». La cultura procede de Inglaterra, que sería la gente civilizada; y el café de los que están recluidos en Cuba. En esta secuencia, mientras David hojea el libro de Vargas Llosa, Diego le confiesa su homosexualidad. Es Ilamativo por la represión de los homosexuales en el momento, pero también porque se trata de una confesión -como el propio libro de Vargas Llosa revela- y la catedral no es otra cosa que el santuario de vírgenes y santos que hay en el apartamento de Diego.

La simbología religiosa está patente en toda la película, sobre todo desde la perspectiva de Diego. Desde la cruz de oro que pende de su cuello, hasta la casa, que está repleta de figuras de vírgenes y santos. No sorprende, por tanto, que haya más de un primer plano de 
las vírgenes que hay en el piso del profesor. La represión religiosa también estaba presente, ya que seguía el estalinismo para combatir la fe, por eso "La Guarida" de Diego lo es en más de un sentido, oculta su religión, aunque manifiesta sus intenciones de exponer sus obras religiosas, lo que supondrá una consecuencia negativa para él.

Por otro lado, se nos muestra la belleza de la ciudad, pero también la pobreza y la destrucción. Diego lleva a David por las calles de La Habana y le revela los secretos arquitectónicos y las cosas hermosas que encierra, acompasada la secuencia con una música triste de piano. Los planos se juntan como si se tratase de un collage que pretende mostrarnos diversas imágenes de la ciudad.

En cuanto a la literatura, embriaga las calles y los muros, como por ejemplos José Martí con: «Los débiles respete, los grandes adelante: esta es una tarea de grandes», pero también las paredes de la casa de Diego, donde cuelgan fotos de Lezama Lima o Charles Dickens, así como querubines o perfiles del indio americano tallado en madera, clara muestra de la identidad y la búsqueda de esta. Esta lucha constante por la libertad precipita el argumento a un final en el que la única manera de alcanzarla es huyendo, por eso Diego le confiesa a David que va a abandonar Cuba: «Pensé que podría decir cosas, pero no. Lo bueno y lo revolucionario es lo que dicen ustedes y se acabó».

\section{ILUMINACIÓN Y BANDA SONORA COMO MARCO CULTURAL}

La iluminación contribuye a la expresividad de la imagen, es por ello que su importancia en la película es relevante, ya que a través de ella se consigue el efecto de verosimilitud a la hora de vivificar el tema tratado. Los colores, por otro lado, forman parte inseparable de la iluminación y establecen la manera por medio de la cual expresar los valores simbólicos de la película. Con respecto a ellos, llama la atención el grafiti, pintado con colores claros y vivaces, que puede pasar desapercibido si no atiendes al mensaje que encierra: "Somos felices aquí», que contrasta con la oscuridad y el derrumbamiento de esas partes de La Habana a las que nos referíamos anteriormente.

Por otro lado, la música es un acompañamiento imprescindible de las imágenes que nos hacen llegar los directores, ya que sin la banda sonora los matices de los sentimientos y las vivencias de los personajes no lograrían hacer mella en el espectador del modo en el que lo consiguen. De la mano del músico cubano José María Vitier, Fresa y chocolate destaca por una incursión espléndida en la cultura cubana. Así, al comienzo del film, y después de que Vivian abandone a David, suena la voz de Ernesto Lecuona (La Habana, 1895_Islas Canarias, 1963) y su canción "Se fue», acompañamiento más que expresivo del dolor que manifiesta el protagonista:
Sin la luz de sus ojos
es cruel mi tormento.
Triste estoy sin su amor,
que robó mi corazón.

Se fue, para no volver. Se fue, sin decirme adiós.

Muy lejos de mí se fue, matando mi ensueño de amor. 
También tenemos que hacer referencia a María Melibrán, Teresa Stratas, Renara Tebali y María Callas, así como a "Adiós a Cuba» de Ignacio Cervantes, de extrema delicadeza, añoranza y pesar o «Ya ves» del cantautor y compositor cubano Pablo Milanés:

\author{
Ya ves \\ y yo sigo pensando en ti \\ como ave \\ que retornará, \\ ya ves \\ y yo sigo pensando en ti.
}

Por tanto la música, en la película, no deja de representar las voces de todos aquellos que en algún momento tuvieron que abandonar Cuba y exiliarse lejos de la tierra natal que les censuraba y delimitaba.

\title{
6. EL RETRATO DE LA SOCIEDAD CUBANA A TRAVÉS DE LOS ESPACIOS
}

La acción de la película comienza en un sucio y desgastado hotel de La Habana, lo que se manifiesta como una clara simbología del estado de Cuba en el año en el que se ambienta la trama. El siguiente lugar que aparece se caracteriza por el contraste, ya que es la cafetería donde Diego y David se encuentran por vez primera. Ese encuentro cambiará la mentalidad del protagonista. Este lugar es indispensable tanto en el cuento como en la película; mientras que el cuartucho derruido del hotel no aparece en El lobo, el bosque y el hombre nuevo, la cafetería -la Catedral del Helado- está presente tanto en el cuento como en la adaptación fílmica. Al tratarse de un exterior, la claridad del día, como ya hemos visto en el análisis de la iluminación, es también muestra de la libertad -la de Diego- en contraste con la reclusión consumida de David -el hotel-.

"La Guarida", sin embargo, es el lugar por excelencia en la película. La trama gira en torno a las reuniones que ambos personajes mantienen allí. El nombre ya es sintomático de lo que representa ese espacio para los protagonistas de la trama. Tengamos en cuenta que una guarida es un refugio para librarse de un daño o peligro, y eso es, precisamente, lo que el piso de Diego representa tanto en la película como en el relato.

El tiempo, por otro lado, es uniforme. En la película no se producen las rupturas temporales que tienen lugar en el relato, por ejemplo. En cuanto al tiempo histórico, como ya hemos expuesto en el contexto socio-histórico concerniente a El lobo, el bosque y el hombre nuevo, se rige por la Revolución que asoló Cuba y por la censura latente que definió todo el periodo. El tiempo histórico, por supuesto, supone también una readaptación del espacio y la necesidad de amoldarlo a la realidad social y cultural por la que transitaba el país.

\section{RECAPITULACIONES}

El lobo, el bosque y el hombre nuevo, mediante un título propio más bien de un cuento fantástico, se adueña de las características de una sociedad y un conflicto histórico innegables. Las desmenuza acudiendo y aludiendo a escritores cubanos de renombre, siendo el más destacado de ellos José Lezama Lima. Le sirven para mostrar la defensa de la identidad 
nacional, pero también de la fe y los derechos de los homosexuales. En relación con esta idea, en la película no hay tanto una defensa de la identidad nacional, sino más bien una necesidad de integración de dicha defensa en la moral y el pensamiento de la población cubana.

Fresa y chocolate rompe los cánones establecidos en la tradición cinematográfica cubana, inclinándose a favor de todas aquellas cuestiones polémicas, y discute acerca de cuántos temas tabú hubiera en la sociedad de su tiempo. Así, el cuento está plagado de lobos que habitan en un espeso bosque sumergido en la Revolución, del que David, el coprotagonista, saldrá con los ojos abiertos y convertido en un hombre nuevo, negando lo que se recoge en el relato: «Yo era su última carta, el último que le quedaba por probar antes de decidir que todo era una mierda y que Dios se había equivocado y Carlos Marx mucho más, que eso del hombre nuevo [...] no era más que poesía» (Paz, 2006: 19-20).

\section{BIBLIOGRAFÍA}

Alonso, A. (2011). "Las "Palabras a los intelectuales" a la vuelta de medio siglo», en Cubadebate, 30 /06/2011. Disponible en:

( http://www.cubadebate.cu/autor/aurelio-alonso/ > [cons.21/05/2019].

AYALA, F. (1975). El escritor y el cine. Madrid, Ediciones del centro.

Carmona, R., (2006). Cómo se comenta un texto fílmico. Madrid, Cátreda/Signo e imagen, $6^{\mathrm{a}}$ ed.

Gimferrer, P. (1985). Cine y literatura. Barcelona, Editorial Planeta, Colección Ensayo.

M.V. (11 de noviembre de 2013). «Homenaje a Fresa y chocolate», en ABC.es. Toledo, 20/11/2013. Disponible en:

«http://www.abc.es/toledo/ciudad/20131120/abci-fresa-chocolate-cibra-201311201316. html ,

[cons.15/05/2019].

PAZ, S. (2006). «El lobo, el bosque y el hombre nuevo», editor: Jonathan Dettman, Northern Arizona University. Disponible en:

http://hamalweb.com.ar/ellobo.pdf [cons.12/05/2019].

PEÑA-ARDID, C. (1996). Literatura y cine. Una aproximación comparativa. Madrid: CátedraSigno e Imagen.

Pujals, G. y ROMEA, Ma C. (coord.) (2001). Cine y literatura. Relación y posibilidades didácticas. Barcelona, Editorial Horsori, Cuadernos de Educación, $n^{\circ} 34$.

UTRERA, R. (1987). Literatura cinematográfica. Cinematografía literaria. Sevilla, Ediciones Alfar. 